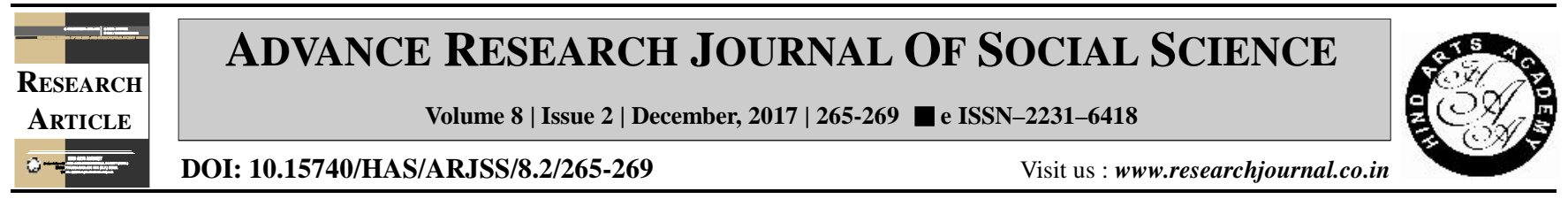

\title{
A study on the knowledge of mothers regarding behavioural problems of children
}

\author{
Jayshree Godara* and Sunita Chouhan
}

Department of Human Development and Family Study, College of Home Science, S.K. Rajasthan Agricultural University, BIKANER (RAJASTHAN) INDIA

(Email: jayshreegodara@gmail.com)

\section{ARTICLE INFO :}

$\begin{array}{lll}\text { Received } & : & 09.08 .2017 \\ \text { Revised } & : & 15.10 .2017 \\ \text { Accepted } & : & 30.10 .2017\end{array}$

\section{KEY WORDS :}

Knowledge of mothers regarding, Educational, Behavioural problem

\section{HOW TO CITE THIS ARTICLE :}

Godara, Jayshree and Chouhan, Sunita (2017). A study on the knowledge of mothers regarding behavioural problems of children. Adv. Res. J. Soc. Sci., 8 (2) : 265-269, DOI: 10.15740/HAS/ARJSS/ 8.2/265-269.

*Author for correspondence

\begin{abstract}
The education of women is not imperative for the benefit for the women only but uplift of the society also. Today, women from all corners started working in government, semi government or private salaried jobs. The entry of women in the workforce brings changes in the structure and function of family. Every member of the family occupies a vital position in the interaction map of the child but among them the role of mother is important and varied. Mother plays important role in the personality development of the children by shaping their intellectual and social behavour. Thus, The present study was undertaken to assess knowledge about the behavioural problems of preschool age (3-6 years) of non-employed mothers. The total sample for the present study consisted of 40 randomly selected (lottery) mothers from four randomly selected residential colonies of Bikaner city. 10 non-employed mothers were selected randomly (lottery) from each selected colony. The data were collected through interview schedule prepared by Gupta (2006). Frequency, percentage, was computed to assess the aspects of the behavioural problems of preschoolers of non-employed mothers. The assessment of knowledge of non-employed mothers revealed that majority of employed mothers had high knowledge about behavioural problems of preschoolers as compared to non employed mothers and knowledge was also found highly significant between employed and non-employed mothers.
\end{abstract}

